\title{
Anish Kapoor: espacialidad en abismo
}

\author{
Anish Kapoor: Spaciality in Abyss
}

\author{
Manuel Lavaniegos \\ Instituto de Investigaciones Filológicas \\ Universidad Nacional Autónoma de México
}

Resumen: A partir de la reciente exposición "Anish Kapoor, Arqueología: Biología" que ha tenido lugar en el Museo Universitario de Arte Contemporáneo (MUAC), de la UNAM, de mayo a noviembre del 2016, se interpretan algunas de las obras exhibidas del trascendental artista anglo-indio, poniéndolas en relación con otras famosas piezas de su producción, y en referencia al contexto del campo expandido de la escultura y el arte contemporáneos. La compleja profundidad de las creaciones de Kapoor, que incorporan el vacío a la morfología de sus proto-objetos o formas autogeneradas, es abordada desde la perspectiva del retorno abstracto/simbólico y poético del arquetipo de "lo matricial" en las artes. También se reflexiona acerca de la dimensión sagrada o metafísica implicada en sus instalaciones escultórico/arquitecturales desde una hermenéutica apofática del arte, que, no obstante posee una fuerte significación estética y política.

AbStRaCt: Based on the recent exhibition "Anish Kapoor, Archeology: Biology" held from May to November 2016 at the Museo Universitario de Arte Contemporáneo (MUAC) of the UNAM, some of the works exhibited by the transcendental Anglo-Indian artist are hereby interpreted in relation to other famous pieces of his production and in reference to the context of the expanded field of contemporary sculpture and art. The complex depth of Kapoor's creations that incorporate the void into the morphology of his proto-objects or self-generated forms is approached from the perspective of the abstract/symbolic and poetic return of the archetypal "matrix" in the arts. This paper also reflects on the sacred or metaphysical dimension involved in his sculptural/architectural installations from the viewpoint of an apophatic hermeneutics of art, which nevertheless has a strong aesthetic and political significance.

Palabras Clave: campo expandido escultórico, Vacío, Svayambh, resurgencias de lo matricial/nocturno, hermeneusis apofática del arte.

KEYWORDS: Expanded sculptural field, Void, Svayambh, Matrix/nocturnal resurgences, apophatic hermeneusis of art.

RECIBIDO: 1 de noviembre de 2016 • ACEPTADO: 16 de noviembre de 2016 


\section{Manuel LaVANiEgos}

Instituto de Investigaciones Filológicas

Universidad Nacional Autónoma de México

\section{Anish Kapoor: espacialidad en abismo}

El arte, la poesía tiene una misión: abrir una ventana a ese otro mundo, que es de hecho el nuestro, en permitir al yo que escape de sus límites y se dilate hasta lo infinito.

MARCEL RAYMOND (1960:18)

Toda creación brota de una oscura matriz original donde se abriga palpitante cuanto no conocemos. De ahí que esa entrada en lo oscuro carezca de orientación predeterminada.

José Ángel Valente (2002: 153)

Muchas de mis obras regresan a la idea de que el espacio sólo está definido hipotéticamente, que hay algo más allá de él. Es una proposición del espacio tratado como una idea poética.

ANISH KAPOOR (en Lampert 2016: 22)

[...] los artistas no crean objetos, construyen mitologías y es a través de esas mitologías como nosotros interpretamos sus objetos.

ANISH KAPOOR (en Baume 2008: 31)

La reciente exposición Anish Kapoor. Arqueología: Biología, que ha tenido lugar en el Museo Universitario de Arte Contemporáneo (MUAC), 
de la UNAM, de mayo a noviembre de 2016, nos ha dado la oportunidad, a los universitarios y al público mexicano en general, de entrar en contacto con un conjunto altamente representativo - debido a la excelente curaduría a cargo de Catherine Lampert, y a la cuidadosa e inteligente instalación - de obras realizadas, entre 1980 y 2016, por el trascendental artista indo-anglo (nacido en Mumbai en 1954, hijo de padre indio y madre judeo-iraquí, emigrados a Gran Bretaña en la década de 1920).

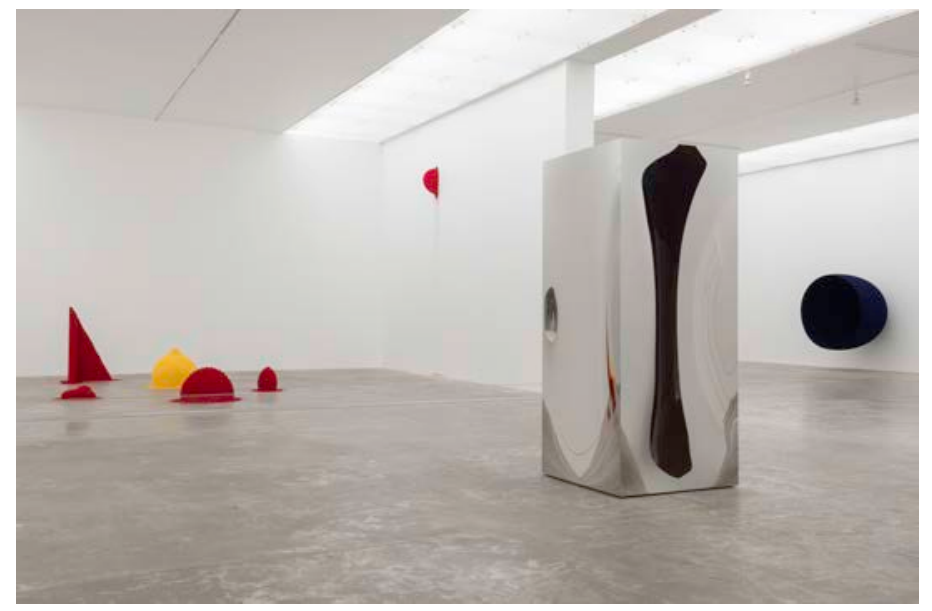

Imagen 1. Anish Kapoor. Vista de exposición. Anish Kapoor. Arqueología: Biología, Museo Universitario Arte Contemporáneo, muac/unam, Ciudad de México, México, 2016. Fotografía: Oliver Santana

Esta muestra (imagen 1) permitió entender el porqué de la expansiva resonancia mundial que ha adquirido en la actualidad la obra de A. Kapoor, por supuesto ligada al inmediato impacto que provocan sus peculiares artefactos, esculturas o instalaciones - ya sea en sus modalidades: de volúmenes cóncavos o convexos reflejantes/refractantes, de honduras y protuberancias cubiertas de polvo intensamente pigmentado, de envolventes membranas elásticas, de cerros de curvilínea pasta petrificada, o de impresionantes dispositivos embadurnados de cera roja, que se desplazan en ralentizado movimiento - sobre la percepción de los espectadores, al grado de suscitar toda una febril algarabía de reacciones a su alrededor. Sin embargo, con un poco más que nos dejemos atraer hacia el radio de gravitación de estos "no-objetos", "objetos 
vacíos", "proto-objetos" o "formas autogeneradas" (en sanscrito: Svayambh, "alumbrado por sí mismo"), como alternativamente gusta denominarlos Kapoor, con un poco más que seamos invadidos por la fuerza de su espacialidad, nos vamos percatando de que entramos en ámbitos desconcertantes, inquietantemente enigmáticos, que hacen que se tambaleen y pierdan pie nuestros habituales parámetros espacio/temporales. Entonces da comienzo el auténtico pasaje iniciático que ofrecen las piezas del artista; que como observaba Horst Bredekamp: "induce[n] a las personas, confrontadas con la falta de barreras, a encontrar una guía dentro de sí mismas" (Bredekamp en Lampert 2016: 21).

De tal suerte que si abrimos nuestra receptividad a su physis de fondo, a la materialidad sensible y significativa de su espacio/tiempo, al cúmulo de presencia/ausencia concentrado en cada una de sus piezas, la densa maleza espectacular/mediática que parasita y recubre - fenómeno que, por lo demás, le ocurre en nuestros días a cualquier evento artístico/cultural relevante- a las "para-esculturas" de A. Kapoor, se evapora como por ensalmo y las obras se nos descubren como verdaderos "hipnóglifos", cual yantras tibetanos, que intensivamente movilizan la imaginación meditativa, reflexiva, como es propio de las grandes obras. Porque, en efecto, las creaciones del artista anglo-indio no sólo irrumpen de manera contundente en el panorama artístico de las últimas décadas del siglo XX y las primeras del XXI, sino que añaden su territorio dialogal - también genealógico - al arte sin fronteras de todas las latitudes y épocas.

Así, el shock psíquico/corporal, a un tiempo inconsciente y consciente, al modo de un vuelco emocional, que el despliegue de los sentidos, sensual, erótico, emanado por las piezas — predominantemente con forma de receptáculos, de recipientes, de agujeros - produce en el espectador, da paso a un deslizamiento modulado de fascinación y terror, que, al alterar las relaciones espaciales del sitio visible y palpable, lo succiona hacia la interioridad de otro espacio, invisible e inefable; pero cuya existencia, tan efectiva como virtual, ha alterado radicalmente las coordenadas físicas de la orientación. Pues, tanto la estructura del objeto construido por Kapoor ("no-objeto" u objeto que alberga vacío) como el espacio arquitectónico que lo contiene son escorados, desplazados, fenomenológicamente dis-torsionados, hacia una nueva 
dimensión pulsante que vibra entre la revelación y el ocultamiento; o mejor, hacia una no-dimensión "proto-formal", desconocida del Ser o metafísica.

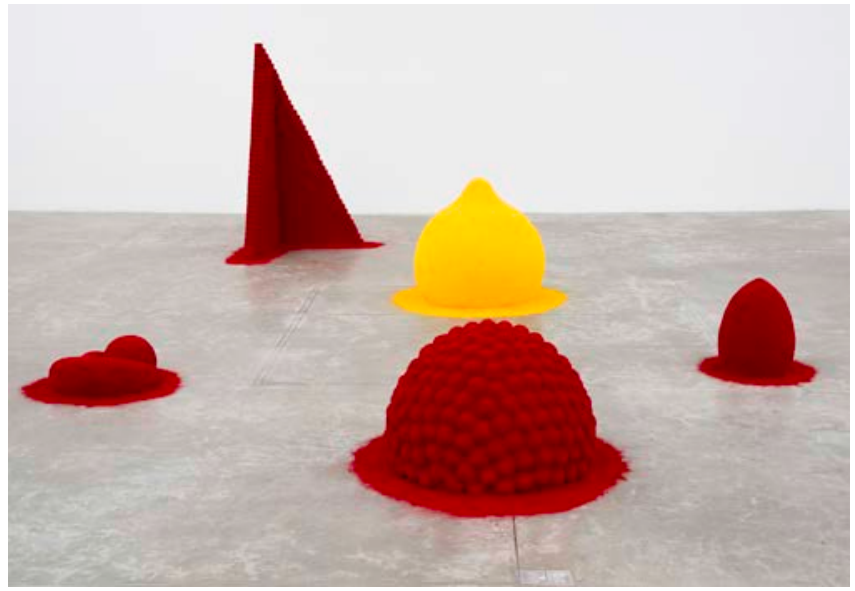

Imagen 2. Anish Kapoor. Para reflejar una íntima parte del rojo-To Reflect an Intimate Part of the Red, 1981. Técnica mixta y pigmento-Mixed media and pigment. 200 x 800 x $800 \mathrm{~cm}$. Cortesía Museo Universitario Arte Contemporáneo, MUAC/unAm. Fotografía: Oliver Santana

Ello ya se encuentra presente desde obras tempranas como $1000 \mathrm{na}$ mes (1000 nombres) (imagen 2) de 1979-1980, la cual se encadena en series "iterativas" (Homi K. Bhabha), en las que el artista cultiva el mismo prodigio de hacer emerger, del suelo o la pared de los recintos, morfologías, a la vez geométricas y orgánicas, completamente espolvoreadas por un solo intenso color - sobre todo rojo, blanco y amarillo, aunque a veces también las hay de azul profundo y negro-, cual si germinaran por sí mismas, especie de jardines paradisiacos o de constelados templos en ciudades de otro planeta. Kapoor está utilizando aquí, por vez primera, la costumbre ritual - vista por él en la India - de recubrir de pigmento nichos y estatuas de culto, lo mismo que los pies y las manos de los devotos en fiestas solemnes. Este recubrimiento causa que las obras irradien un aura en torno de sí, suavizando sus definidos contornos y borrando la mano del artifex, que pasa a ser un catalizador, un jardinero, propiciante para que las fuerzas generatrices se desenvuelvan. Los discos, escalas, pirámides triangulares o cónicas, semiesferas 
y poliedros de diversa índole, semejantes a semillas, corolas, frutos, senos, madejas, capullos, cristalizaciones, montículos, cráteres, palacios o astros están en trance de aparecimiento, parcialmente sumergidas sólo sobresalen a nuestra visión - se ha comentado- como icebergs, emanados de otro mundo pleno de vida que desconocíamos y que, sin embargo, pulsa debajo de nuestros pies y a nuestro lado, confinado pero inquietante, imprevisible e invencible en su potencia, únicamente a la espera de ser "nombrado" para florecer. Vienen a la mente las palabras de Proclo: “¡Oh tú a quien se invoca bajo nombres tan diversos! ¿Cómo podré llamarte? ¡Oh tú que eres el único a quien no puede llamarse!”. De este modo, 1000 names se halla dotado de la cualidad Svayambh, nos devela maquetas de un espacio que también podría ser denominado “ontogénico" (Fernández del Campo 2006: 36). ${ }^{1}$

El arte de Kapoor sabe conjugar con inusitada destreza el diseño de las formas más puras o abstracto-geométricas básicas, a menudo saturadas de un solo color, monocromáticas, a cuya contemplación desnuda nos habituó el arte abstracto (Kandinsky, Malévich, Mondrian, etc.), con su poderosa y, a la vez, sutil o brutal, encarnación matérica; para esto basta con referirnos a Untitled (Sin título) de 1992 (imagen 3), vertical monolito de piedra, cuyo corte accidentado de piedra arenisca aloja en su interior un rehundido rectángulo pigmentado de negro/azul, cual portal que se nos abre a una profundidad insondable; probablemente se trata de la pieza más sobriamente hierática de toda la muestra.

Desde el principio de su trayectoria artística Kapoor irrumpió en el "campo expandido" - transdisciplinario y multidimensional - de la escultura y, en general, de las artes plásticas que, si bien se gestó desde las vanguardias de la primera mitad del siglo xx (Brancusi, Giacometti, J. Arp, Picasso, Julio González, Miró, Calder, Boccioni, Tatlin, Ródchenko, Moholy-Nagy, Pevsner, Duchamp, H. Moore, B. Hepworth, etc.), cobraría sobre todo una proliferante diversidad a partir del fin de la Segunda Guerra Mundial; por ejemplo: en las exploraciones del vacío de E. Chillida, J. Oteiza o P. Serrano; las construcciones de arte cinético (J. Tinguely, Pol Bury, J. Le Parc, etc.) y del op-art (Cruz-Diez, J. R. Soto,

1 “Ontogénico" es un término utilizado por la hinduista Eva Fernández del Campo, que relaciona esta obra con los 1000 nombres del dios Śiva en la mitología puránica (2006: 36). 


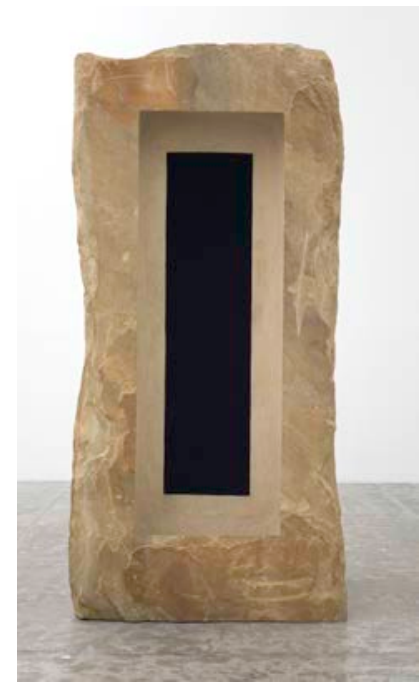

Imagen 3. Anish Kapoor. Sin título-Untitled, 1992. Piedra arenisca y pigmento-Sandstone and pigment. $230 \times 230 \times 103 \mathrm{~cm}$. Cortesía Museo Universitario Arte

Contemporáneo, MUAC/UnAm. Fotografía: Oliver Santana

Y. Agam, etc.); las esculturas de ensamble y en despliegue (David Smith, Anthony Caro, E. Hauser, etc.); el minimalismo (C. Andre, R. Bladen, Dan Flavin, Donald Judd, Sol LeWitt, Robert Morris, R. Ryman, Daniel Buren, Richard Serra, etc.); el land-art (Christo y Jeanne-Claude, Richard Long, Robert Smithson, M. Heizer, Dennis Oppenheim, A. Goldsworthy, Walter de Maria, Nancy Holt, etc.) y el performance-art (Dadá, Yves Klein, P. Mazoni, John Cage \& M. Cunningham, Jannis Kounellis, etc. y, sobre todo, Joseph Beuys con su proyecto de "escultura social"). ${ }^{2}$ De tal manera que en su obra el artista indio-anglo conjuga, como lo expresa Norman Rosenthal, "monumentos formales (escultura), cromáticos (pintura), móviles (teatro y espectáculo) y espaciales (arquitectura)" (Rosenthal 2010: 46), sobre una amplia gama polimatérica. Una complejidad creativa que se aviene de manera idónea con una obra que, lejos de poder estar identificada con el exotismo de un cliché hinduista o con un acrítico mainstream globalizado, se articula en un lenguaje auténticamente intercultural, transcultural y capaz de expresarse con versatilidad en diferentes modalidades estilísticas.

2 Véase Lucie-Smith 1994; Goldberg \& Monnin 2004; Domino 2005; Guash 2000. 
André Breton se sirvió de la expresión "vasos comunicantes"3 como metáfora para intercomunicar los flujos pulsionales del inconsciente con la lucidez de la consciencia, las fuerzas de la revolución con las de la poesía, bajo designio surrealista. El poeta José Lezama Lima escribió sobre los "vasos órficos" $"$ para descifrar efectivamente vasijas áticas que tenían pintado como tema al mítico cantor Orfeo y que delataban su originario parentesco eleusino, en una continua oscilación retornante del caos inframundano al olímpico cosmos uraniano. Mientras que el filósofo anglo-indio Homi K. Bhabha, viejo amigo y dialogante de Kapoor, recurre, para hablar de su obra, al motivo de la "vasija" planteado por Heidegger como "modelamiento del vacío"5 — una idea sostenida, con antelación de siglos, de modo incomparable en el Tao Te Ching (55 XI) de Lao Tse.$-{ }^{6}$ A nuestra vez, podemos sostener que hay una vocación kapooriana de confeccionar prevalentemente recipientes (por ejemplo, entre muchos otros, de modo subrayado: Pot for Her (Vasija para ella) de 1985, Pot (Vasija) de 1991 o Shire (Santuario) de 1987), modelar vasijas, conductos, tubos, bolsas, túneles, pozos, atanores... todo un repertorio vascular, recipientario, que se realiza insuflado de abismo. Al modelar el vacío de sus piezas Kapoor lo amplifica hacia lo abismático, fabrica una especie de vasijas en abismo - vase en ab $\hat{\imath}$ $m e-$, que nos abren sus bocas y, por medio de su vacío configurado,

3 "Vasos comunicantes" se define en el diccionario como: "Conjunto de dos recipientes o de dos ramas de un tubo en los cuales, por estar en comunicación y estar igualmente sometidos a la presión atmosférica, un líquido alcanza la misma altura. Puede aplicarse en singular, por ejemplo a la cañería de conducción de agua con que se salva un desnivel de terreno" (Moliner 1990: 1444). Véase André Breton 1973.

4 Aludimos a su libro Introducción a los vasos órficos (Lezama Lima 1971: 183-192).

5 Véase Bhabha 2010a:171-177.

6 Treinta radios convergen en el cubo de una rueda, y merced a su vacío, el carro cumple su misión.

Modelando la arcilla se hacen vasijas, y merced a su vacío, las vasijas de arcilla cumplen su misión. Horádense los muros con puertas y ventanas, y merced a su vacío, la casa cumple su misión.

Y así, del ser (you) depende su uso, y del no-ser ( $w u$ ), que cumpla su misión (Lao Tse 2006: 327). 


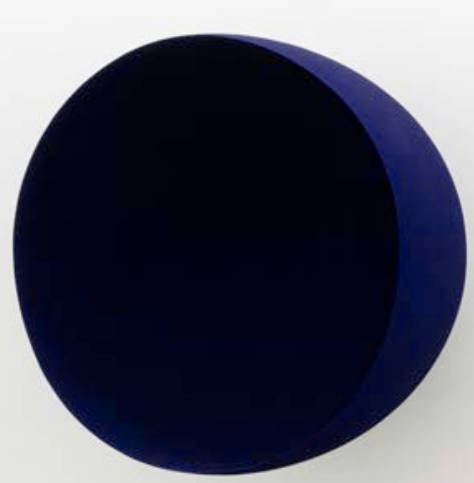

Imagen 4. Anish Kapoor. Vacío-Void, 1989. Técnica mixta y pigmento-Mixed media and pigment. $200 \varnothing$ x 152.5. Colección particular-Private collection. Cortesía Museo Universitario Arte Contemporáneo, MUAC/UnAm. Fotografía: Oliver Santana

"añaden más vacío al espacio", cautivando al espectador en el límite de su precipicio y, así, “cumplen su misión” (imagen 4). De esta manera, los vasos comunicantes diseñados por Kapoor contienen un espacio de disimetría irreductible entre las superficies que recorremos y la intuición del abismo (abgrûnt) hacia el que nos precipitan. Podríamos, asimismo, usar el símil de que sus piezas trazan "cintas de Moebius" que, al imperceptible desliz de un plano a otro, provocan la peripecia hacia una segunda cinta o dimensión invisible, la vía del vacío, elongación del tiempo/espacio, precisamente en el "intersticio ciego entre dos cóncavos espejos que se reflejan" y que le obsesiona a Kapoor. El Tao Te Ching (VI 50) designa, junto a la vasija, al valle como símbolo del Gran Vacío:

Valle, espíritu, inmortal;

llámese "hembra misteriosa".

El umbral de la "hembra misteriosa"

es la raíz del Cielo y de la Tierra.

Continuamente, así es como parece existir

y su eficiencia nunca se agota

(Lao Tse 2006: 38). 
Al respecto de When I am Pregnant (Cuando estoy gestando) de 1992 (imagen 5), se puede advertir que frontalmente parece no haber nada, sólo el simple muro blanco de la galería. A lo más, viendo con atención, una pelusilla, un leve halo de sombra sobre la blanca pared. Únicamente al irnos desplazando, poco a poco, va emergiendo de modo oblicuo su abovedado relieve. Nuestro deslizamiento, paralelo al muro blanco, se convierte en un -involuntario y voluntario - ir rodeando la suave protuberancia que va creciendo contorneada en luces y sombras, paulatina y suave, pero rotunda en la inocente epidermis de la pared. Hemos observado, palpado, en mínimos segundos y con un par de pasos, el sorprendente proceso del embarazo de la sólida pared, que, ahora, blanda y dilatada, se yergue latiendo su grávida blancura; preñada por el vacío exhibe momentos de una plenitud en gestación. De la invisibilidad interior y enigmática de la materia, aparentemente inerte e impenetrable, del muro se nos revela toda una secreta existencia, que palpita en el sutil intersticio transicional entre la piel de yeso y el macizo enladrillado del lienzo, interespacio deseante que se aloja y propulsa un virtual ente desde sí, que a partir de la inmaterialidad hace presente el embrión de vacío, como turgencia de un "proto-objeto".

Imagen 5. Anish Kapoor. Cuando estoy gestando-When I am Pregnant, 1992. Técnica mixta-Mixed media. Dimensiones variables-Variable dimensions. Cortesía Museo Universitario Arte Contemporáneo, MUAC/UnAM. Fotografía: Oliver Santana 
Anish Kapoor confiesa que estando en Uluru (Ayers Rock), Australia — "el lugar más religioso que he visitado en mi vida" - , anotó la idea de "forma blanca sobre pared blanca", que daría lugar a When I am Pregnant. Dice, también, "tenía que crear una forma que pudiera estar presente y no presente [...] Como usted sabe, me obsesiona la idea de lo «proto» y me encanta la de la gestación” (Baume 2008: 47).

La estudiosa del arte de la India y autora de una magnífica monografía sobre A. Kapoor, Eva Fernández del Campo, apunta que la expresión en inglés "When I am Pregnant", literalmente traducida al castellano "cuando estoy preñado", resulta incorrecta, ya que estar "preñado" no se puede aplicar a un hombre; la incorrección semántica es, sin embargo, perfectamente intencional en Kapoor. La autora escribe:

El arte para Anish Kapoor está vinculado a la idea de maternidad; esto no sólo queda patente en la gran cantidad de iconos femeninos que representa, sino en el hecho de que reconozca como femenina, al igual que la mitología hindú, la energía dinámica del universo (Śakti). Por otro lado, el artista ha afirmado en varias ocasiones que su parte creativa es femenina, que reconoce la necesidad de asumir en sí mismo lo femenino para llevar a cabo una liberación fundamental (Fernández del Campo 2006: 71).

Eva Fernández del Campo señala también que el artista indio-anglo fue en un tiempo asiduo lector de Psicología y alquimia de C. G. Jung y que para su concepción del arte la experiencia de los opuestos arquetípicos de lo masculino y lo femenino es condición previa para la experiencia de la totalidad, que resulta de su conjunción o cópula amorosa. Hay que agregar que la concepción desarrollada por el psicólogo suizo es, asimismo, afín a la mayoría de las culturas míticas arcaicas, antiguas y tradicionales, no sólo a la de la India. Para Jung la necesaria integración del aspecto femenino (Anima) inconsciente de la psique masculina y del aspecto masculino (Animus) inconsciente de la psique de la mujer forma parte estructurante del proceso de individuación para el desarrollo tanto del "Yo" como del paso hacia el "Sí mismo" (Selbst); proceso equivalente simbólicamente al de la formación alquímica de un Andrógino interior, capaz de reunirse con el Anima Cosmi, obten- 
ción de la Lapis Philosophorum. En la religión india, especialmente en el tantrismo, el icono del linga-yoni, fusión del símbolo fálico (linga) y del símbolo de la vulva femenina (yoni), encarnan la unión de los contrarios, generadora creativa del universo; también representada en la imagen andrógina de Śiva Ardhanārīśara. Una recreación de esta androginia o hermafroditismo alquímico lo viene a mostrar, sin duda, la asombrosa escultura en mármol rosado, llamada Mollis, de 2003, que conjunta, con turbadora organicidad, la polaridad fálica y vaginal en la morfología de una nueva entidad, que integra la diferencia sin evitar su tensión, al tiempo que la remansa en nacaradas ondulaciones. Kapoor repite, en 2008, el mismo diseño de sus contornos en otra pieza, de escala más pequeña y con la sofisticada superficie hecha de acero inoxidable reflejante y ultra-facetado, a la cual denomina In-Out Fractured Surface (Superficie quebrada de entrada y salida). Ambas obras recuerdan los amuletos de linga-yoni o "huevos cósmicos", cargados de virtud apotropáica, usados por los creyentes en la India; así como a la célebre escultura de conjugación andrógina de Constantin Brancusi: Maiastra, dedicada al pájaro mítico de las leyendas y los cuentos rumanos y de la que realizó varias versiones en diferentes materiales. ${ }^{7}$

No sólo el destilado "grado cero" que es When I am Pregnant - a la manera del Cuadrado blanco sobre blanco (1918) pintado por Kazimir Malévich - participa de este ámbito en torno al carácter fundamentalmente matricial de la fuente de la vida y la creatividad - concepción análoga, también, a la noción platónica de la Khôra, matriz o nodriza de alcances inclusive "proto-ontológicos", 8 o a la citada "Hembra Misteriosa" del taoísmo-, sino las mencionadas Pot for Her, Pot y Shire; asimismo Mother as a Mountain (Madre como una montaña) de 1985; las cavidades circulares o semiesferas vaciadas de honda pigmentación azul oscuro: Void (Vacío) de 1989, Mother as a Void (Madre como un vacío) y Madonna, ambas del periodo 1989-1990. Con definida figura vulvar se alza en medio de un cúmulo de piedras de antracita Black Fire (Fuego negro) de 1990. De decidida impronta matricial son, también, la mayoría de los circulares espejos convexos, con sus superficies refle-

\footnotetext{
Véase Brancusi 1997.

8 Véase Derrida 1995.
} 
jantes/refractantes a menudo coloreadas, para ser dispuestos en interiores, los cuales absorben las imágenes del mundo en torno y las desvían, re-forman sus proporciones y puntos de fuga, a menudo invirtiendo por completo la imagen de las cosas, transfigurando sus sustancias y sometiendo al "yo" a licuefacción; con su extrañado reflejo descorren el velo de $M \bar{a} y \bar{a}$ cotidiano de lo real hacia una consistencia inaparente, hacia los sitios primordiales del misterio, ahora, descubierto desde su reflexivo seno. Principalmente los azogues teñidos de rojo sangre disuelven las cosas en una liquidez femenina: placentaria, menstrual, nutricia, que se derrama como oscura luz de las cosas; como en Blood Mirror-IV (Espejo de sangre-IV) de 2013, presente en el MUAC, o los tres círculos de espejo que componen Her Blood (La sangre de ella) de 1998 y la instalación Seven Ways In (Siete maneras de entrar) del 2000, umbrales de distinta materia por los que bulle la sangre e inclusive brilla derramada en espejeante charco.

En este cauce de femineidad simbólica pueden colocarse también la serie de piezas llamadas White Dark (Oscuridad blanca); la inmensa irradiación azafranada de Yellow (Amarillo) de 1999; la anillada forma cóncavo/convexa de pan de oro instalada en el Mausoleum am Don, en Graz, Austria, en 1997; el espejo convexo colocado en el altar de la Kunst-Station St. Peter, en Colonia, Alemania, en 1996; y el inmenso bloque de alabastro de ovalada horadación instalado frente a la iglesia de San Giusto, en Volterra, Italia, en 1997. Inclusive, las diversas variaciones (2010-2015) de la perturbadora - tupida de vello o manchada de carbón-Dirty Corner (Esquina sucia), cuya versión metálica entre rocas, en el Château de Versailles, en el 2015, fue agredida por un grupo de racistas. ${ }^{9}$

Todas estas obras no dejan de remitirnos a las formas femeninas de la sexualidad, hacia sus contornos redondeados y turgentes, asimismo, hacia sus hondos orificios envolventes y oscuros - senos, vientres, ombligos, vulvas, vaginas, labios, bocas - atrayendo a su profunda cavidad interior, cubriendo dentro de su bóveda uterina, nutriendo de sus sustancias, sumergiendo en un viaje por dentro de sus membranas amnióticas e irrigadas de sangre; también en la acepción griega de amneiós: de

9 Véase Lampert 2016: 21. 
vasija con la que se recogía la sangre de los corderos (amnós) sacrificados. Pues el arquetipo de la Gran Madre,$^{10}$ abarcadora de la Naturaleza toda - "que tiene a la vasija como su locus dilecto"-, se halla cargado de la esencial ambivalencia o polaridad de la vida misma; dadora de la existencia la diosa siembra, a la vez, la semilla de la muerte; sus símbolos se desdoblan y son tan contradictorios como complementarios. En Mesopotamia simultáneamente es Inanna y Ereshkigal, las diosas hermanas, la de la luz celeste y la de la oscuridad infernal; en la India es la divina Śakti que es, a la vez, Kālī, la Madre Terrible, la negra diosa de la muerte; en el cosmos mexica podría ser representada como dualidad entre Xochiquétzal y Coatlicue o Mictlancíhuatl. ${ }^{11}$ En la dirección siniestra el símbolo de la vagina dentada, presente en muchas sociedades "primitivas", es elocuente evidencia del terror a la castración y a ser devorado totalmente por la Madre Terrible.

En entrevista con Marjorie Althorpe-Guyton, Kapoor declara:

Hay un gran temor a la mujer. Es algo que el pensamiento indio reconoce abiertamente. Personifica a la Madre Terrible como deidad Kălī. El momento del origen, en tanto que concepción del principio y como vía para entender mi propia actividad, es de primordial interés para mi obra. Gran parte de la imaginería que utilizo es femenina. Los primeros trabajos constituidos con polvo, White Sand, Red Millet, Many Flowers y To Reflect an Intimate Part of the Red, sondean el origen femenino. Es como si descubriera lo femenino en mí. He reconocido este hecho como una realidad, y eso me permite trasladar mi interés a otros temas. Creo que es una liberación fundamental (Althorpe-Guyton 2016).

Cuando Kapoor persiste en la vocación matricial que impregna su labor no hace otra cosa que remontarse a abrevar del venero de los primeros símbolos ya cultivados por el arte paleolítico y neolítico ${ }^{12}$ prolongados universalmente en todas las culturas, constituyendo con sus obras un enérgico afluente de ese gran cauce transhistórico de recreación por las artes del Ewig-Weibliche (el Eterno femenino), como le denominaba

\footnotetext{
Véase Neumann 2009.

Véase Solares 2007.

12 Véase Gimbutas 1996.
} 
Goethe. Por supuesto, que ello había tenido un desarrollo prolífico en el arte moderno; en el terreno de la escultura basta recordar a Brancusi, Giacometti, Miró, Henry Moore, Barbara Hepworth, I. Noguchi y Louise Bourgeois, entre muchos otros creadores.

La dinámica de la red de símbolos de la feminidad tiende a entretejer, a inervar, todos los planos de la realidad, extendiendo las secuencias de su manifestación en un encadenamiento astral-bio-socio-psicológico, técnico y espiritual. ${ }^{13}$ El antropólogo de lo imaginario Gilbert Durand ha mostrado cómo es que la estructuración de estas figuraciones obedece al orden prevalente del "Régimen Nocturno" de lo imaginario (2004), y siguiendo la idea jungiana de enantiodromía (movimiento de compensación simbólica, psíquico/cultural, hacia la polaridad inconsciente contraria, despreciada y negada por la polaridad hegemónica de una época histórica, que se desata, precisamente, cuando ésta última entra en crisis), Durand investiga las vertientes marginadas, siempre resurgentes, de la nocturnidad matricial - antifrásica y mística - a lo largo de la historia occidental dominada por el patriarcalismo - diairético, ascensional y esquizomorfo- del "Régimen Diurno". De tal manera, no resulta extraño que las insurgencias artísticas y culturales de "retorno a la Gran Madre" (E. Fernández del Campo dixit), que ya había sido asumido apasionadamente por la nocturnidad sublime del Romanticismo y a las que también pertenece la obra de Kapoor, se intensifiquen, a menudo incluso desesperadas, en el contexto actual en que la globalización capitalista incrementa sus dominios neototalitarios sobre la naturaleza y los hombres.

Seguramente, una de las piezas en que la significación matricial alcanza una resonancia cósmica sobre nuestro cuerpo/psique sea At the Edge of the World-II (Al borde del mundo-II) de 1998. Esta inmensa bóveda de intenso rojo, de ocho metros de diámetro y cinco de pro-

13 Sin pretender ser para nada exhaustivos, mencionemos algunas simbolizaciones dilectas del universo matricial: la Tierra, el Mar, la Luna, la Estrella, la Montaña, el Valle, la Cueva, la Casa, el Templo, la Cúpula, la Ciudad, la Vasija, la Copa, el Cofre, el Velo, el Espejo, la Barca, la Cuna, el Manantial, el Pozo, la Fuente, el Lago, el Agua, la Leche, la Miel, la Sangre, la Noche, la Oscuridad, el Fuego, el Inframundo, la Grieta, la Mina, la Joya, el Abismo, la Tumba, la Planta, la Flor, el Fruto, la Semilla, el Huevo, a lo que hay que añadir un sinnúmero de morfologías animalísticas y personificaciones antropomórficas. 
fundidad, exige, de hecho, que nos situemos debajo de ella. Dentro del cobijo de su cautivante domo encarnado, nuestra mirada se eleva hacia el fondo de su techo, el cual, sin embargo, se torna sorprendentemente insondable. Opera el traslado a una suerte de ingravidez infinita del interespacio "al borde", en el umbral del límite del mundo. Aquí están puestas en plena actividad ciertas orientaciones clave de la poética cosmizadora kapooriana: ${ }^{14}$ "Vamos venid aquí. Puedo atraeros profundamente y mi espacio se infiltrará en el vuestro" (Kapoor en Bhabha 2010b: 31).

Me interesa la escultura que implica al espectador hacia la revelación específica con el espacio y el tiempo. El tiempo en dos niveles: uno, narrativa y cinemáticamente como materia del paso a través de la obra y,

14 Otra extraordinaria muestra de que la imaginación plástica consigue configurar visiones cósmicas, con extrema impronta meditativa, es su obra Laboratory for a New Universe (Laboratorio para un nuevo modelo del universo) del 2006 (imagen 6). En la cual, dentro de un transparente bloque rectangular de acrílico estalla una burbuja de aire, su explosión de vacío se abre paso desintegrando, astillando, la materia compacta del poliedro y, en ese mismo instante, queda cristalizada. Es el congelamiento, la detención, de una milésima de segundo, cual modelo del BigBang originario del universo pensado por los físicos, que podemos observar como insecto atrapado en una gota de ámbar. Pero, al mismo tiempo dispara una especulación cosmogónica sobre la potencia del "vacío", sobre el desatamiento de su energía virtual transformando la urdimbre de los elementos; entendiendo al vacío según el pensamiento oriental, al menos taoísta, como la otra cara o dimensión de la plenitud del ser en el universo, puesto que si no existiese el $l i$ ("aliento") de vacío no podría haber espacio para la trasmutación, para la manifestación de la vida de todos los seres. Para esta temática véase el maravilloso libro de François Cheng, dedicado a las bases espirituales de la pintura china antigua, Vacío y plenitud (1993); que consideramos resulta convergente con las ideas de Kapoor en torno al vacío. Así, esta maqueta paradigmática del nacimiento de un universo da qué pensar; pues el movimiento suspendido de la irrupción de esa célula de aliento en el macizo de acrílico produce una inversión, que es una interpenetración de los contrarios en la transparencia. El vacío inicial gana en materialización de sus contornos en la medida que avanza y, a la inversa, se abren surcos de desmaterialización desde el interior del bloque, para dar espacio al crecimiento y vuelo del nuevo protoplasma, del nuevo microcosmos irradiante. Lo lleno se torna vacío y lo vacío se va llenando, vórtice o medusa de luz que agita el prisma apacible, es sólo por esta tensión interpenetrante que se capta la plenitud generadora del espacio. Esta generación de espacialidad desde el interior entregado a la pura refracción luminosa se produce, también, en la más pequeña pieza expuesta en el MUAC: Gold Corner (Esquina dorada) de 2014, un verdadero remanso dentro de la vertiginosa exposición, cual discreto chopo en una olvidada orilla, del que brotan incesantes destellos esperanzadores. 


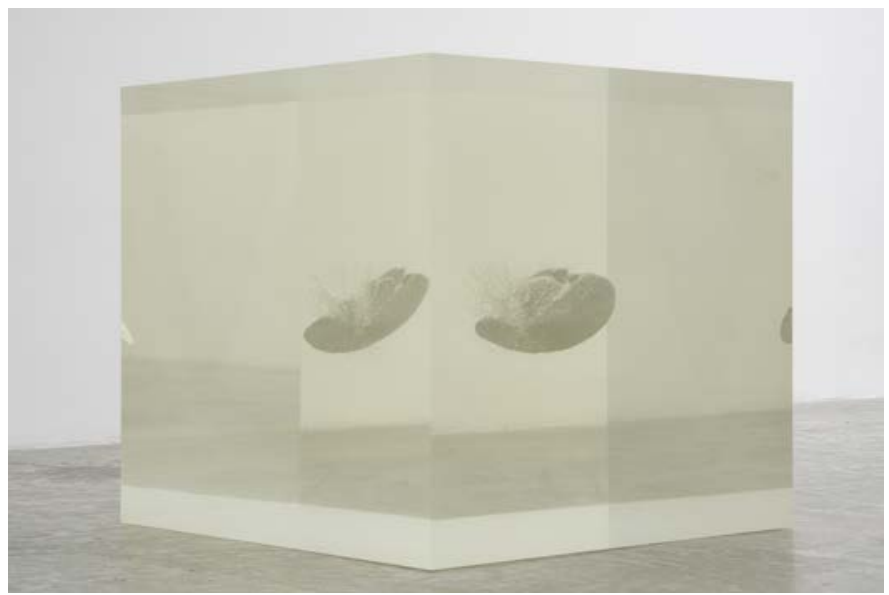

Imagen 6. Anish Kapoor. Laboratorio para un nuevo modelo del universo-Laboratory for a New Model of the Universe, 2006. Acrílico-Acrylic. 123 x 134.1 x $132.7 \mathrm{~cm}$. Cortesía Museo Universitario Arte Contemporáneo, MUAC/UnAM. Fotografía: Oliver Santana

el otro, como una elongación literal del momento. Esto tiene que ver con la forma y el color y la propensión del color a generar ensueños. Consecuentemente, espero, una elongación en el tiempo. El espacio es igual de complejo; el espacio contenido en el objeto debe ser más grande que el objeto que lo contiene. Mi objetivo es separar al objeto de su condición de objeto (Kapoor en Lampert 2016: 24).

Estas claves se ligan con la observación de Homi K. Bhabha:

Quizá lo más valioso que se pueda apuntar para interpretar la obra de Kapoor es que la presencia de un objeto, más que la mera vacuidad, puede conseguir que un espacio esté más vacío. Ese vacío excesivo, generador, se aprecia por doquier en su obra. Es un proceso que Kapoor asocia con la acción de fuerzas opuestas pero afines: la retirada y la revelación, "el hecho de acercarse a una sima que perfila y constituye una nueva superficie que mantiene abierta la pregunta de dicha superficie, su tensión" (2010a: 171).

Asimismo, A. Kapoor ha declarado: "He querido siempre convertir el rojo de la tierra y el cuerpo en cielo" (en Warner 2016: 88). Y, específicamente, con relación a At the Edge of the World se pregunta, a modo 
de reto: “¿Cómo puede uno hacer un horizonte entero? - Sólo hay dos maneras de hacerlo: una es hacer un agujero en el suelo, la otra es colgar algo encima de tu cabeza" (en Fernández del Campo 2006: 171). ${ }^{15}$

Si un buen ejemplo de la primera de estas opciones fue la construcción Descent into Limbo (Descenso al Limbo), para la Documenta IX de Kassel, en 1992, de la segunda alternativa lo es Al borde del mundo. Se trata, de nuevo, de deslizar al espectador fuera de las coordenadas de su mundo habitual, justo llevarlo al contorno - labios - limítrofe(s) del abismo. Umbral que comienza a succionarlo en cuanto cruza, imperceptiblemente, hacia el campo gravitacional de su irradiación cromática, hasta estar por completo inmerso en la atmósfera rojiza que se apodera de todo el espacio perceptual; es el borde en que se suscita la experiencia de vértigo. Auténtico "movimiento de transición: invierte, afirma y niega" - dice Kapoor - , orilla y recinto paradojal, que al abrazar con su encendida y caliente iridiscencia al espectador, en el mismo momento, lo lanza a la plenitud vacía de un cielo imposiblemente rojo. El "Rubedo", ese rojo alquímico en esta especie de atanor que nos contiene, confeccionado por Kapoor, prosigue jalonándonos en su trayectoria invertida, va absorbiendo para sí las valencias de la lejanía azul del cielo diurno y de lo abismal negro de la inmensidad nocturna. En todo caso, la intensidad crepuscular de lo solar pulsa, aquí, en favor del apogeo de una luna roja, que nos arroja a su útero sideral, tiñendo con su sangre nuestros cuerpos.

En At the Edge of the World ocurre pues, como le gustaba enunciar al pensador del Límite, Eugenio Trías (1991), el "resplandor del límite", que el habitante fronterizo puede captar, reflexionar y recrear. En esa zona liminar producida por el performance que desata el "no-objeto" creado por Kapoor, ocurre, también, el instante de "revelación y retirada" del más allá que le da límite a nuestro mundo y que, inevitablemente, se retrae a su ausencia, al "cerco hermético" de donde procede, y que, incondicionado, se sustrae a presencia, pero que, al menos por un instante - de coalición de lo material y lo inmaterial, de lo conocido y

15 Que evoca los polos entrecruzados nombrados "Cuerpo espiritual" y "Tierra celeste" por Henry Corbin (1996), al referirse a la topología del Mundus Imaginalis del misticismo mazdeísta y chiíta. 
lo desconocido, de los límites siderales y los límites biológicos, de la profundidad de lo externo y lo interno, de lo físico y lo metafísico-, puede ser vislumbrado, experienciado. Al borde del mundo, con su inquietante murmullo de silencio, no deja de emitir, como todos los "objetos esquivos" producidos por Kapoor, la reverberación sombría de su acción de "fisión" (H. K. Bhabha), casi a nivel subatómico; ya que, inundados por su aura enrojecida, acude a la mente la ineludible asociación con la capucha del hongo y la radiación escarlata de una explosión nuclear, última sangría del mundo, cuya posibilidad, en efecto, bordea los límites de nuestro mundo.

Tanto At the Edge of the World como, en general, todas las obras elaboradas por el artista anglo-indio - que por su vacuidad configurada consiguen "que un espacio esté más vacío"-, provocan una fuerte conmoción en el recinto arquitectónico en que son ubicadas, ello se expresa de manera más ostensible en los macroproyectos de intervención arquitectural (de "arte público") emprendidos por Kapoor en diversos sitios y monumentos emblemáticos de las ciudades. En estos ocurre una trasmutación radical de la constructiva espacial, que, sin demoler o trepanar los contornos dados por la fábrica arquitectónica, los subvierte o des-construye desde dentro, por el poder de la nueva espacialidad introducida por sus vasos o pasajes escultóricos en abismo, por los que, ahora, transita el espectador/paseante. Siguiendo un camino inverso a los característicos empaquetamientos de edificios, puentes o entidades naturales realizados por Christo y Jeanne-Claude, cuyas telas envolventes clausuran la funcionalidad cotidiana de las arquitecturas y paisajes, proyectándolos hacia una suspensión fantasmal, Kapoor, más bien, dota a las edificaciones con epidermis, tegumentos, musculaturas y cavidades que amplifican, complejizan y precipitan sus estructuras, conduciéndolas a encrucijadas enigmáticas en una tesitura de laberinto.

Esto sucede con Leviathan, colocada, en 2011 en el Grand Palais de París, que, con sus tres grandes bolsas esféricas de vinilo negro, interconectadas y dispuestas en trébol, irrumpía dentro de la arcada armazón de acero y vidrio del edificio. El espectador encontraba acceso al "vientre de la ballena", íntegramente engullido por la panza negra, se veía obligado, para comprender la forma, a rodear el edificio, pudiendo únicamente captar aspectos parciales de los amenazadores globos en hinchazón aposentados en el palacio. 
Hay una serie de cosas - declara Kapoor - , una cosa dentro de otra; en las dimensiones correctas, nunca puedes imaginar el objeto [...] porque uno tiene que pasar por un proceso en la poética propia para reconstruir el objeto internamente [...] Siempre he pensado que la escultura que revela su plano, vista desde arriba, está muerta [...] Y la propuesta aquí es que el interior del objeto y el objeto exterior son distintos entre sí (Bhabha 2016: 100).

La re-edificación tensional que Kapoor produce con Leviathan en el Grand Palais estaba imbuida de una declarada intencionalidad estéticopolítica, al citar al Leviathan (1651) de Tomás Hobbes, que, en los albores de la modernidad, radiografiaba al monstruo del poder soberano del Estado para el control de la "lucha de todos contra todos". El artista estaba también interesado, del mismo modo que el adelantado inglés, por la razón del movimiento de los cuerpos de los individuos y de la sociedad, y de los "ídolos" que estos movimientos generan. Kapoor daba a la experiencia del espectador una aguda situación interrogante acerca del poder y del Estado, ¿qué le ocurre a los cuerpos individuados que, al mismo tiempo, están y no están - son y no son - adentro del Leviathan?, ¿la corporeidad artificial del monstruo que, acaso, no se erige por el andamiaje vital de aquellos?, ¿cómo es el espacio que producen sus mutuas relaciones? Aquí, de manera análoga a como Christo y Jeanne-Claude pusieron en jaque el Reichstag berlinés, en 1995, recubriéndolo de interrogantes acerca de la existencia o inexistencia de la democracia.

Mientras tanto, en Tarantara (1999) y Marsyas (2002), Kapoor, en entrevista con Sune Nordgren, afirma "estar haciendo lo contrario que Brancusi [recuérdese La columna sin fin]: volver lo de dentro hacia fuera" (en Fernández del Campo 2006: 86). En ambas obras, a través de la intervención interespacial de una piel se redimensionan los ámbitos arquitectónicos. Con membranas vivamente rojas, que, por medio de aros y tensores, despliegan sus enormes túneles y embudos, vuelve a operarse la incidencia de "un movimiento de transición: [que] invierte, afirma y niega", porque se exponen tanto el haz como el revés del sanguíneo tegumento, la interioridad y exterioridad de la pieza, que, por su gran escala, invierte el equilibrio: del adentro y el afuera de las construcciones que recorre, éstas devienen en partes integradas de la pieza 
misma. La escultura ha puesto a su servicio a la arquitectura, de nuevo, en beneficio de la topología poética y metafísica kapooriana.

Tarantara, instalada en un abandonado gigante molino en Gateshead, al lado del río Tyne, cerca de Newcastle, Inglaterra, con forma de una inmensa trompeta, conecta las dos fachadas a través de su tubo vacío que recorre todo el largo interior de la enorme mole (45 metros de altura por 51 de largo y 25 de ancho), produce el mágico efecto de un tobogán o salto dimensional de "cinta de Moebius". Así, desde la intimidad visceral de ese raro vacío, el visitante/paseador se siente y se ve lanzado hacia las alturas del clamor trompetístico ¡Tarantara!, cuyos contrapuntos espaciales elevan también al edificio - a punto de desaparecer, convertido en escombros - a una temporalidad heroica.

Pero, es con su Marsyas, instalada en la sala de turbinas cruciforme de la Tate Gallery de Londres, donde el monumental deslizamiento espacial, a través de tres magnas trompas asimétricas de membrana roja - que han sido comparadas con la morfología de las "trompas de falopio" del aparato reproductivo femenino-, alcanza una dimensión, incontestablemente, sacrificial, impregnada, a la vez, de tragicidad y misticismo. A. Kapoor recurre a la narrativa mítica griega del Sileno ${ }^{16}$ - reputado como el inventor de la flauta de doble tubo, aunque se contaba que había sido en realidad inventada por Atenea, la cual, al ver deformadas sus mejillas cuando soplaba por el instrumento, había maldecido y arrojado la flauta lejos de sí, junto a un río de donde la recogería Marsias - , quien, ufano de la música que tocaba con la flauta, según él la más bella del mundo, retó a Apolo a tratar de superarla con la música de su lira. Apolo aceptó el desafío con la condición de que el vencedor podría disponer a su antojo del vencido, además instó a Marsias a tocar su flauta en posición invertida, como él lo hacía con la lira. La perfección de la música apolínea resultó vencedora en la contienda. Apolo, entonces, colgando a Marsias de un pino, procedió cruelmente a desollarlo. Se cuenta que Apolo arrepentido rompió su lira y trasformó a Marsias en río. La terrible escena del desollamiento de Marsias ha sido plasmada muchas veces por la pintura. Son especialmente elocuentes los cuadros que le dedican José de Ribera y el Tiziano. Kapoor, atento

16 Véase Grimal 1993: 333-334. 
a todos los motivos del mito y sus variaciones, ${ }^{17}$ y muy particularmente conmovido por la paradójica y genial versión de Tiziano (El castigo de Marsias, 1570-1576), ${ }^{18}$ recrea el mito con la potencia abstracta de su arte, desprendiéndose de todas las figuraciones anteriores depura al extremo para preservar y resaltar el sentido sacrificial y redentor del mito de Marsias; que entrega su arrancada piel, ahora convertida en una inmensa flauta doble, que emite su música inaudible por el vacío en que circula la vida. Toda la superficie corporal ${ }^{19}$ del Sileno se ha transfigurado en la plenitud de los caminos de un cielo enrojecido, cuyas profundidades el visitante no puede poseer de golpe, sino que tiene que ir sondeando por su elástica extensión.

El filósofo Amador Vega, en sus Cuatro lecciones de estética apofática (2005), relaciona la instalación Marsyas con otra obra de Kapoor con explicita referencia místico-religiosa: The Healing of Saint Thomas (La curación de Santo Tomás) de 1989, esta última, añadiríamos, vinculada a la más penetrante herida en la pared de Arqueología: Biología (2016), que, justamente, le da título a la exposición del MUAC. Para el estudioso, el desnudo y escueto motivo del corte rojo sangre en el muro simbolizando la herida en el costado de Cristo, hecha por la lanza de un soldado durante la crucifixión - “de la que manó sangre y agua”- , y que, al introducir el apóstol un dedo en esta llaga, vino a ser la cura, visible y palpable, de la incredulidad de Tomás, su paso o "conversión" de la cruel y oscura zozobra e incredulidad a la luminosidad resurrecta de la fe en la senda del alma, no es la ilustración o explicación, moralizante

17 Atinadamente, Eva Fernández del Campo testimonia que Kapoor también tuvo en cuenta, durante el proceso de su Marsyas, a la divinidad mexica de Xipe-Totec ("nuestro señor el desollado"), en cuyo nombre los sacerdotes se revestían, en el ritual, con la piel desollada de los sacrificados simbolizando con el cambio de piel la fértil regeneración periódica de la Tierra. (Fernández del Campo 2006: 86-87).

18 El cuadro de Tiziano, El castigo de Marsias, 1570-1576 (óleo/lienzo: 220 x 204 cm, Palacio Kromeriz, República Checa), estuvo expuesto en la Tate Gallery simultáneamente a la instalación de Kapoor.

19 Rosa Martínez, en su texto, refiriendo otra obra de A. Kapoor - Islamic Mirror, instalada en la Sala Sharq Al-Andalus, del Monasterio de Santa Clara, Murcia, España, en 2009- cita, con pertinencia, a Gilles Deleuze, en Logique du sens (1969): "Lo que es más profundo que cualquier fondo es la superficie, es la piel, Aquí se forma un nuevo lenguaje esotérico que es en sí mismo su propio modelo y su realidad" (2009). 
o pedagógica, de una historia, sino que la obra de arte de Kapoor acoge su significación transhistórica y anagógica más profunda.

El motivo desnudo del corte en la pared quiere dotar al elemento narrativo concreto de una dimensión significativa más amplía; no se trata de desvincularlo del contexto cristiano para convertir dicho motivo, la herida, en un objeto abstracto, pero quiere recordarnos que la potencia de lo simbólico no se agota en su comprensión literal (Vega 2005: 142).

A diferencia del nihilismo que reina en otras interpretaciones conceptualistas y deconstructivistas del arte contemporáneo, y acerca de la significación de los peculiares usos que el arte hace de la abstracción, que, por descontado, también alcanzan a diversas interpretaciones de la obra de Kapoor, Amador Vega ha insistido en el carácter específico de lo que nosotros llamaríamos la abstracción-simbólica, que utilizan determinados artistas contemporáneos, algunos de los que se mueven en el sentido definido de una "estética apofática". Esta última análoga y emparentada en Occidente, como A. Vega explica, con las vertientes de la filosofía mística de los autores europeos, entre los siglos XIV y XVI, que desarrollaron una doctrina de la imagen que afecta por igual a la experiencia estética y religiosa del hombre - perspectiva hermenéutica desarrollada también por Alois M. Hass y Victor I. Stoichita-. Así enfocada, la consecución de la "separación del objeto de su objetualidad para unirlo con el espacio" que, explícitamente, posee para Kapoor una "función religiosa", procede de una separación-abstracción o sustracción de las representaciones figurativas a la mano; "desfiguración ritual" que, al modo de una ascesis espiritual, liberadora de la ganga -fútil, fugaz o anquilosada - de las representaciones miméticas, crea iconos de tendencia apofática de gran potencia, como la mandorla de los salterios, concentrada solamente en la herida del cuerpo de Cristo como tema central de meditación de la Pasión. La radiante u oscura abertura cóncava de la mandorla posibilita el "traspaso" o la "brecha", la ranura infinita del "deshacimiento" del yo y sus deseos terrenales, hacia el "nacimiento de Dios en el alma humana", según el pensamiento del Maestro Eckhart; pues se ha de transitar al "abismo" (abgrûnt), donde se alcanza el encuentro místico de Dios con el hombre, en el "fondo" 
del alma o "fruto de la nada" (Vega 2005: 143-145). En esta orientación de una abstracción artística apofática A. Vega encuentra afinidades entre la multiforms de Mark Rothko, las cruces de Joseph Beuys, el spazialismo de los lienzos rajados de Lucio Fontana, los cuerpos ahuecados y las cajas vacías de las esculturas de Jorge Oteiza, la Emergence de la serie The Passions de Bill Viola y las obras de A. Kapoor. ${ }^{20}$

Refiriéndose concretamente al Marsyas, Amador Vega escribe:

La escultura de Kapoor aúna la problemática del sacrificio del cuerpo, tal como la recibió Rothko en su lenguaje de la desfiguración de la imagen, y relativa a la herida. En la instalación de la Tate, los extremos que representan la piel de Marsyas son aperturas por las que introducirse en el interior del cuerpo sacrificado. Si aquellas primeras pinturas de Rothko (Sacrificio de Ifigenia, etc.) - en las que la acción central del sacrificio hacía pensar en la desmembración del cuerpo, cuya consecuencia pictórica fue la fragmentación de la imagen -, se sostenían sobre el principio nietzscheano de la destrucción del principium individuationis, aquí se da un paso más en la representación del camino que conduce a la unidad mística, tanto del mito trágico, en clave nietzscheana, como del relato evangélico de la pasión en clave eckhartiana (2005: 150-151).

En el horizonte de esta hermeneusis apofática del arte, planteado por A. Vega, el símbolo de la herida del "cuerpo de Gloria" resucitado, en el episodio del apóstol Tomás, en clave de la mística cristiana, muestra: "en su vacuidad la pobreza espiritual, el acto de despojamiento (kénosis) que lo ha llevado a la muerte (Flp 2,7) y su regreso a la vida" (Vega 2005: 154). En resumen, su sentido apunta hacia un triunfo espiritual sobre la muerte. Esta clave simbólica final que se aplica, asimismo, al Marsyas y, en general, podríamos sostener, al sentido del conjunto de la obra de Anish Kapoor, quizá puede servirnos para enfrentar las últimas piezas sobrecogedoras, siniestras, y revulsivas confeccionadas por el

20 A esta deriva de correspondencias planteadas por A. Vega, quisiéramos sugerir, por nuestra parte, las pinturas de Gunther Gerzso, realizadas en la década de los sesenta del siglo xx, cuando cortes, heridas o rajaduras incidieron en sus fascinantes arquitecturas pictóricas abstraccionistas y de empaque prehispánico, entreabriéndolas a una dimensión enigmática. Véase Eder I994, así como nuestra tesis (Lavaniegos 2004). 
escultor y colgadas en el MUAC, en la misma sala en que se inscribe la mencionada herida Arqueología: Biología, se trata de Mother, Mother (Madre, madre, imagen 7); Tongue memory (Memoria de la lengua) y 3 Days... (3 días...), las tres de 2016.

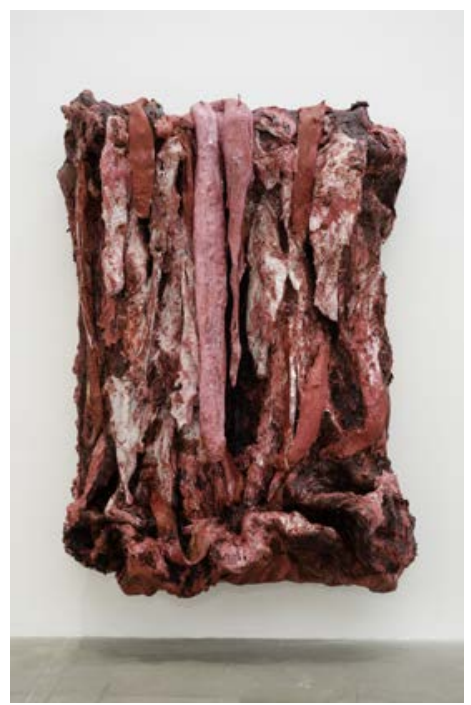

Imagen 7. Anish Kapoor. Madre, madre-Mother, mother, 2016. Técnica mixta, silicón y pigmento-Mixed media, silicone work. 230 x 150 x $60 \mathrm{~cm}$. Cortesía Museo Universitario Arte Contemporáneo, MUAC/UnAM. Fotografía: Oliver Santana

En su trepidante texto sobre la exposición del MUAC, Jaime Soler Frost explaya la siguiente secuencia acerca de estas obras:

De Rembrandt y Velázquez a Bacon y a Soutine, a Kapoor, la res abierta en canal se concibe palpable. Manos de carnicero la penetran, desprenden el sebo, los tendones, una aglomeración de silicón carmesí, un despliegue de carne recién muerta, los cuerpos caídos, los desencarnados (Ayotzinapa), los rincones sucios, allí donde ya nadie inhala y exhala, nada se expande y se contrae, restos materiales , los despojos del quirófano arrojados al cesto de los residuos patológicos [...] (2016: 70-72).

Todas estas asociaciones son, por supuesto, perfectamente válidas y se desprenden del brutal pathos que emana de los grandes trozos "informes" de cadáveres colgantes, violentamente exhibidos y que dan la im- 
presión de estar aún chorreantes, en estado de coagulación o en avance de putrefacción de sus carnes sangrantes. Como en su momento lo hiciera Rembrandt, con barroca melancolía, ante la res abierta en canal, o Soutine, con sufriente arrebato expresionista, no sólo frente a un animal desgarrado, sino pintando mujeres, hombres y paisajes salpicados por la hemorragia en torbellino del flujo vital, ${ }^{21}$ de modo análogo Kapoor penetra en la dolorosa meditación del memento mori, vuelve a contagiarse, sin pudor ni asepsia alguna, de la mancilla de la carne y la sangre $^{22}$ adherida a los misterios de la finitud existencial de la condición humana. Sin embargo, las tres contundentes obras distan radicalmente de caer en un hiperrealismo o en una mera estetización de lo repulsivo y lo abyecto, por el contrario, el informalismo matérico ${ }^{23}$ al que se entrega Kapoor se encuentra transido emocionalmente tanto de angustia, rabia, dolor, como de piedad-terror (phóbos) y piedad (éleos) son, según la Poética de Aristóteles, los componentes propios de la emoción trágica. Los escenarios de despojos que habían contenido, sostenido y sustentado la intensidad de la vida, ahora, exhaustos, lacerados, descoyuntados y aullantes, nos miran a nosotros; imploran a través de sus jirones sanguinolentos, desde los pliegues nos llaman hacia su oscuro fondo, a no olvidarnos de la vida que una vez fue pletórica y aún parece que sus postreros suspiros no han concluido y todavía nos sustentan anhelantes. No os olvidéis de la "madre", de la "lengua", apenas han transcurrido algunos días, algunas horas... no abandonéis sin más esos cadáveres, aún insepultos (Antígona), ¡vedles de nuevo! La alusión a no olvidar, a la intensa relación entre memoria e imaginación como fuente creativa de la vida es otra de las caras insistentes de la labor escultórica de Kapoor; los intersticios de interrogación abisal entrevistos en estos despo-

21 Renatta Negri, acerca del cuadro del Buey desollado (1925) de Chaim Soutine, escribe: "Directamente inspirado en Rembrandt, este tema ha excitado a Soutine hasta el paroxismo: ha visto y explotado todas las posibilidades expresivas, creando un inmortal poema al rojo de la sangre, al grito de la carne lacerada y rota, al temblor de la vida que no quiere extinguirse" (Negri 1967: 5).

22 Para la profunda polisemia inherente a la simbólica de la sangre, generadora de tabús a través de las culturas, véase Roux 1990.

23 Dice A. Kapoor: “[...] la totalidad de la tradición escultórica se concentra en la forma positiva. Lo negativo en la escultura se ha basado en una relación simbólica con lo positivo. En los últimos años he estado trabajando para tratar de dejar atrás la forma y abordar la falta de forma" (MUAC 2016: 99). 
jos se hermanan, así, con la recóndita estructura de Memory (Memoria) del 2008. De esta manera, la dolorosa herida infringida al muro y las violentadas corporalidades colgantes que exhibe el artista se ofrecen al espectador como un descensus ad inferos, pero esa catábasis posee simultáneamente un transfondo de redención, una vía de anábasis, a través de su carne.

Por último, quisiéramos referirnos a la compleja instalación circular en lentísimo movimiento - una hora exacta tarda su radio metálico en dar la vuelta a su circuito de 12 metros de diámetro, cual una gran noria, el radio o fuerte brazo jala en su rotación un imponente cubo rectangular de acero, que empuja una nutrida masa de cera roja y en su arrastre va arrojando sus residuos, que van conformando un cono truncado, cuyo irregular cráter a cada rotación altera sus contornos - My Red Homeland (Mi patria roja, imagen 8), construida en 2003, y colocada en el MUAC; la cual forma parte de las obras del artista, dotadas de cinetismo efectivo por medio de un motor, subrayando de esta manera literal la condición perseguida de Svayambh (autogenerado). Como, acaso, el lector se ha podido dar cuenta a lo largo del presente texto, para el artista indio-anglo la cuidadosa elección del espacio arquitectural o paisajístico, su rigurosa disposición de acuerdo a sus componentes contextuales, tanto físicos como histórico/culturales y políticos, es tan esencial como la morfología de la obra misma. Ambos factores configuran la abstracción simbólica de la obra, la unidad espacio/temporal concreta de su instalación/acontecimiento. Por ejemplo, la obra denominada directamente Svayambh de 2007, que es un enorme bloque de esa peculiar cera carmesí que, igualmente, se desplaza a ritmo ralentizado, y que tiene forma parecida a un tren supurando sangre, en una de sus instalaciones, atravesó, cual si se tratara de túneles, los arcos de medio punto de las orgullosas salas de la Haus der Kunst de Múnich, erigida por Hitler con la función de exhibir el arte nacionalsocialista, conforme el siniestro vehículo atravesaba los arcos iba dejando sus pegajosas salpicaduras sanguíneas en los marcos y paredes de las salas. Aun señalando la abierta polivalencia de significaciones que, sin duda, posee la pieza, no se podían dejar de evocar aquellos trenes que llevaron - como lo expresó Norman Rosenthal"el destino de los millones de personas que, hacinados como animales, cruzaban Europa en dirección a los campos de exterminio" (2010: 45). 


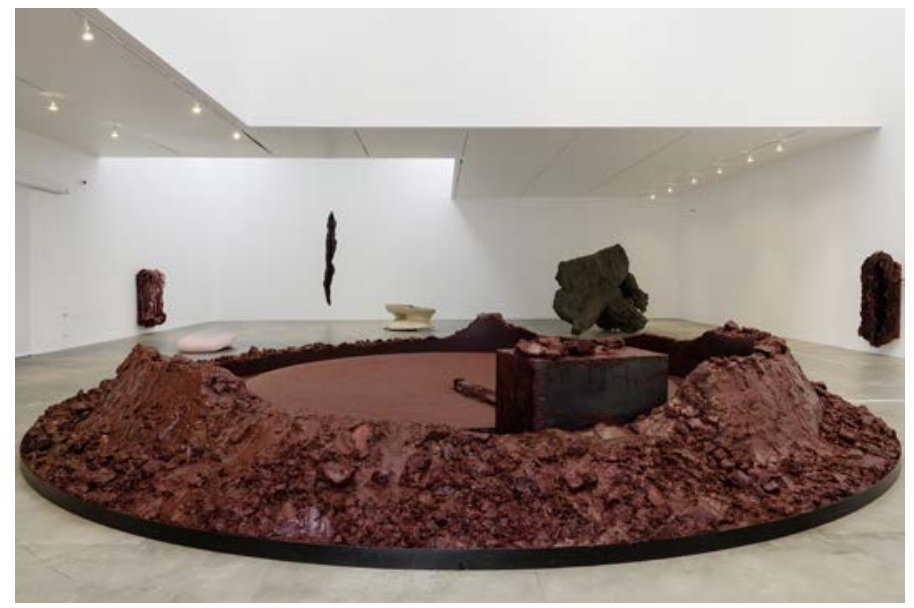

Imagen 8. Anish Kapoor. Mi patria roja-My Red Homeland, 2003. Cera, acero y motorWax, steel and motor. $1200 \mathrm{~cm} \emptyset$. Cortesía Museo Universitario Arte Contemporáneo, MUAC/UNAM. Fotografía: Oliver Santana

My Red Homeland, con su despaciosa e implacable rotación puesta ante nuestros ojos, vuelve a tener una espacialidad paradójica, alude a la siempre resbalosa identificación imaginaria con la "patria", al terruño en su localidad, y también a la Tierra planetaria en su significación de todo lo viviente (Zoé); al modo de un gran reloj que marca el ritmo imperceptible de la erosión por el tiempo rastrillando (Crono) su cráter rojo de sangre como enigmático centro del mundo. Pensamos que Kapoor fue sumamente reflexivo al destinar la colocación de esta obra - "tocando tierra" - en el lugar preciso del MUAC, atendiendo a dos sincronizaciones de fuerte calado: una primera, coyuntural, de valencia actual, de emergencia, en un país que, por todos sus rincones, supura la sangre creciente de miles de víctimas inocentes a manos del crimen organizado aliado a la corrupción de los grupos de poder que controlan los aparatos del Estado.

Una segunda, que hunde sus raíces en el tiempo de más largo aliento de una memoria milenaria, que le otorga su valencia "arqueológica" porque no lejos se encuentra la "pirámide circular", con basamento de cono truncado, de Cuicuilco (Preclásico, 500-300 a. C. aproximadamente), otra espacialidad que se edificó acogiendo el ciclo retornante sagrado del cosmos y cuyo altar central se hallaba teñido con pigmento 
rojo cinabrio. ${ }^{24}$ En el mismo entorno geológico cercano, conformado por la lava sedimentada arrojada por los volcanes Xitle y Ajusco, se asienta otro segundo macrocírculo simbólico de edificación contemporánea, que dialoga con el yacimiento de Cuicuilco, nos referimos al Espacio Escultórico, de Ciudad Universitaria; un ruedo monumental abierto al cielo, de creación colectiva, ${ }^{25}$ que con 120 m de diámetro y configurado por 64 módulos triangular/piramidales circunscribe una gran área de rocas volcánicas y que, como espejo de tierra, cuyo vacío aloja un cúmulo de piedras surgidas del inframundo, refleja el tránsito del sol y las estrellas ritmado por su circuito. Se trata de una obra que se adapta a la topografía ecológica del sitio, que bien puede ser valorada de land-art, y que constituye uno de los más significativos monumentos - si no es el que más - de cu. De tal suerte que establecer la imbricación dialógica de estos tres grandes redondeles escultórico/arquitectónicos no resulta descabellado, y cada uno resulta iluminado por los otros. Así, por esta triplicación de creaciones y el entrecruce concéntrico/excéntrico de ondas que las constelan se pone de relieve la fuerza paraboloide desatada por la exposición de Anish Kapoor.

Si el artista tituló la muestra Arqueología: Biología (imagen 9) como un desafío que excita a pensar en una coimplicación de saberes, que indudablemente es cierta porque al explorar el pasado, aparentemente muerto, se le revive trayéndolo a iluminar y nutrir con su sangre a la vida presente y futura, al mismo tiempo, una mirada biológica y arqueológica que no se articule sobre la mediación poética del vacío abierto a los misterios escondidos de lo otro, y permanezca anclada en el mero dominio del neopositivismo científico/tecnológico, nunca hará justicia a la "capacidad de infinito" que el hombre finito resguarda en los abismos de su corazón, como pensaba Blaise Pascal. De manera similar, al contemplar una obra de Kapoor, el filósofo Homi K. Bhabha escribió: "[...] en una ocasión escuché la voz del vacío surgir de una pared" (2010a: 175).

24 Véase Kubler 1983; López Austin y López Luján 1996.

25 La obra colectiva del Espacio Escultórico, inaugurada en 1979, fue concebida conjuntamente por los escultores Helen Escobedo, Manuel Felguérez, Matías Goeritz, Hersúa, Sebastián y Federico Silva. 


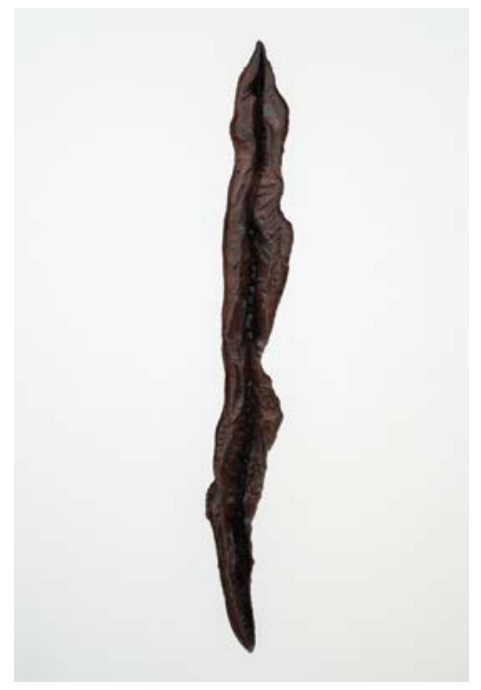

Imagen 9. Anish Kapoor. Arqueología y biología-Archaeology and Biology, 2007.

Técnica mixta-Mixed media. 488 x 122 x $50 \mathrm{~cm}$. Cortesía Museo Universitario

Arte Contemporáneo, MUAC/UnAM. Fotografía: Oliver Santana

Hasta aquí hemos querido compartir con el lector nuestro muy personal recorrido - para nada exhaustivo ${ }^{26}$ y sí relativo y singular - de

26 Por ejemplo, han quedado fuera de nuestro comentario, entre otras obras, el inquietante conjunto de los grandes montículos de churros o de cordones grisáceos de pasta de concreto - que fueron producidos por medio de una máquina programada que iba derramando porciones de determinado grosor - y que ocupaba toda una amplia sala de la exposición, titulado: $G a G u M a$, de 2012. Paisaje raramente orgánico que con el infantilizado balbuceo de su nombre evoca, a la vez, el absurdo resultado del azaroso juego de un niño gigante con sus heces, las acumulaciones de un gran estercolero, las ruinas de una civilización grotesca o las altas y accidentadas estalagmitas de un gran cañón formadas por efectos de una erosión milenaria; paradójico paraje de meandros, donde lo intencional fragmentario se torna en enormes cúmulos in-intencionales, formaciones de lo informe.

O, también, Place Under (Lugar abajo) de 2015, colosal pieza de resina y tierra, que reúne todas las connotaciones de lo matricial de las que hemos venido hablando y en la cual la remisión a lo originario o primordial se confunde íntegramente con una anfractuosa morfología geológica.

Asimismo, C-Curve (Curva-C), de 2007, inmenso espejo curvo de acero inoxidable, que ocupaba toda una sala y que con su doble faz: cóncava/convexa sometía toda la espacialidad del entorno a las más elásticas alteraciones dependiendo de nuestro más leve movimiento. De estas obras se podrían proseguir amplías meditaciones. 
la formidable exposición de A. Kapoor, emprendiendo, al mismo tiempo, algunos desvíos por otras obras no presentes en esta muestra y, sin embargo, muy representativas dentro de su poética, así como atendiendo a penetrantes comentarios expresados por el propio artista indio-anglo y por expertos en su producción. Hemos insistido en que la voluntad de forma, voluntad de arte (Kuntswollen, para usar el término de Alois Riegl), del artista se orienta decididamente en un sentido matricial, con sus fuertes connotaciones simbólicas de corporeidad sexual y materialidad sensible de índole nocturnal y místico, con su tremenda ambivalencia generadora de la vida y portadora de la muerte, que, a través de sus receptáculos, nos traslada, en su instante/acontecimiento, hacia lo abismático de nuestro más remoto origen (útero insondable) y de nuestro oscuro destino último (tumba insondable). También en la peculiar asociación que Kapoor sostiene entre esta femineidad generatriz y el vacío, concebido en sentido muy oriental como la otra cara de la plenitud, creando sus peculiares "noobjetos" o "formas autogeneradas" (Svayambh), que añaden con su vacío más espacio al espacio que los contiene, provocando un vértigo atrayente hacia su interioridad, además de desencadenar la experiencia extática de fundirse con la otredad, del ir adentro de su piel viajando por la cinta de Moebius de su haz y revés. Si Aristóteles afirmó que "el Ser tiene muchos modos de manifestarse", Kapoor proclama que "hay diferentes tipos de vacío". El vacío en sus obras cosmiza la espacialidad, llena de ausencia al Ser, volviéndolo poroso y nos abre a sus dimensiones ocultas, al más allá del espacio o hacia una dimensión metafísica.

Tal vez se considere que los nombres o palabras filosóficas "metafísico", "ontogénico", "trascendente" para designar a ese otro espacio más allá, que Kapoor consigue suscitar con sus obras, son palabras riesgosas, que están cargadas de un sobrepeso conceptual lleno de equívocos especulativos y que pueden opacar eso a lo que intentan aludir, lo cual, por supuesto, es lo decisivo. ${ }^{27}$ El traslado liminar al punto de vértigo es

27 Como hemos podido observar a lo largo de este ensayo, el mismo A. Kapoor es clarividente en el uso de las palabras, cuando, por ejemplo, declara: "Estoy convencido de que las obras de arte, o digamos más bien las cosas del mundo, no sólo las obras de arte, se pueden crear con autenticidad. Si se hacen con autenticidad, en el sentido de poseerse a sí mismas, son hermosas. Si carecen de autenticidad, el ojo es un instrumento muy rápido, y muy preciso...La idea de la autenticidad en la realización no sólo tiene que ver con la verdad. Tiene que ver con el encuentro entre lo material 
lo decisivo, el papel que juega el vacío configurado en obra como catalizador de una experiencia de pasaje a los ámbitos ignotos, tan cercanos y a la vez tan lejanos, que moran en las íntimas fronteras del sentido. Se trata tan sólo de captar la profundidad del vacío que late en las piezas de Anish Kapoor; esa vibración del Mysterium fascinans y del Mysterium tremendum, como caracteriza el fenomenólogo Rudolf Otto "lo sagrado". Así, también las palabras "hacen aparecer", aunque no sea sino para abrir a ese: su vacío — hacia lo innombrable de la experiencia-.

\section{Bibliografía}

Baume, N. (2008). Anish Kapoor: Past, Present, Future. Boston, Institute of Contemporary Art.

Bнaвнa, H. K. (2010a). “Anish Kapoor: cómo se crea la vaciedad”, en Museo Guggengheim Bilbao, Anish Kapoor. Bilbao, Turner: 171-177.

- (2010b). "Objetos esquivos: el arte de fisión de Anish Kapoor”, en Museo Guggengheim Bilbao, Anish Kapoor. Bilbao, Turner: 24-35.

- (2016). "Extractos de dos conversaciones con Anish Kapoor", en MUAC, Anish Kapoor. Arqueología: Biología. Ciudad de México, MuAC-Unam/ Editorial RM: 96-103.

Bredekamp. (2016). "Conversación de A. Kapoor con Nicholas Baume”, en

Museo Universitario de Arte Contemporáneo, Anish Kapoor. Arqueología: Biología. México, MUAC/UnAm/Editorial RM: 18-25.

Breton, A. (1973). Antología (1913-1966). M. Bonnet (sel.). T. Segovia (tr.). Madrid, Siglo XXI.

Corbin, H. (1996). Cuerpo espiritual y Tierra celeste. Del Irán mazdeísta al Irán chiíta. Madrid, Siruela.

Cheng, F. (1993). Vacío y plenitud. Madrid, Siruela.

DERrida, J. (1995). Khôra. Córdoba, Alción.

Domino, C. (2005). À ciel ouvert. L>art contemporain à l’échelle du paysage. París, Scala.

Durand, G. (2004). Las estructuras antropológicas del imaginario. México, Fondo de Cultura Económica.

y lo inmaterial... [Una] cosa existe en el mundo porque tiene coherencia mitológica, psicológica y filosófica. Ahí es cuando algo se crea auténticamente..." (Kapoor en H. K. Bhabha 2010a: 175). 
Fernández del CAmpo, Eva (2006). Anish Kapoor. Donostia-San Sebastián, Nerea.

Gimbutas, M. (1996). El lenguaje de la Diosa. Oviedo, Dove/GEa.

GoldberG, I., y F. Monnin. (2004). La sculture moderne. París, Scala.

Grimal, P. (1993). Diccionario de mitología griega y romana. Barcelona, Paidós.

GuAsh, A. M. (2000). El arte último del siglo XX. Madrid, Alianza.

Jung, C. G. (2011). "Psicología y alquimia”, en C. G. Jung, Obra completa, vol. 12. Madrid, Trotta: 183-243.

Kubler, G. (1983). Arte y arquitectura en la América precolonial. Madrid, Cátedra.

LAMPERT, C. (2016). “Arqueología: Biología”, en Museo Universitario de Arte Contemporáneo, Anish Kapoor. Arqueología: Biología. México, Museo Universitario de Arte Contemporáneo/Universidad Nacional Autónoma de México/Editorial RM: 18-25.

Lao Tse (2006). Tao Te Ching. Los libros del Tao. Edición y traducción del chino de Iñaki Preciado Idoeta. Madrid, Trotta.

Lezama Lima, J. (1971). Introducción a los vasos órficos. Barcelona, Barral.

López Austin, A. y L. López Luján. (1996). El pasado indígena. México, Fondo de Cultura Económica/El Colegio de México.

Lucie-Smith, E. (1994). Movimientos artísticos desde 1945. Londres, Destino/Thames and Hudson.

Moliner, M. (1990). Diccionario de uso del español. Madrid, Gredos.

Museo Universitario de Arte Contemporáneo (2016). Anish Kapoor. Arqueología: Biología. México, Museo Universitario de Arte Contemporáneo/Universidad Nacional Autónoma de México/Editorial RM.

Museo de Santa Clara de Murcia (2009). Anish Kapoor: Islamic Mirror. Murcia, Museo de Santa Clara de Murcia.

Museo Guggenheim Bilbao (2010). Anish Kapoor. Bilbao, Turner.

Negri, R. (1967). Chaim Soutine. Buenos Aires, Codex.

Neumann, E. (2009). La Gran Madre. Una fenomenología de las creacioens femeninas del inconsciente. Madrid, Trotta.

Raymond, M. (1960). De Baudelaire al surrealismo. México, Fondo de Cultura Económica.

Rosenthal, N. (2010). "Svayambh”, en Museo Guggengheim Bilbao, Anish Kapoor. Bilbao, Turner: 44-47.

Roux, J.-P. (1990). La sangre. Mitos, símbolos y realidades. Barcelona, Península. Rubercy, Eryck De, y Le Buhan, Dominique (1997). Constantin Brancusi. Ramón Ibero (tr.). Barcelona, Polígrafa. 
Solares, B. (2007). Madre terrible. La Diosa en la religión del México Antiguo. Barcelona, Anthropos/Universidad Nacional Autónoma de México.

Soler Frost, J. (2016). “Abismo sin sombra”, en Museo Universitario de Arte Contemporáneo, Anish Kapoor. Arqueología: Biología. Ciudad de México, Museo Universitario de Arte Contemporáneo/Universidad Nacional Autónoma de México/Editorial RM: 66-74.

TríAs, E. (1991). Lógica del límite. Barcelona, Destino.

VAlente, J. Á. (2002). "Chillida o la transparencia”, en J. Á. Valente, Elogio del calígrafo. Ensayos sobre arte. Barcelona, Círculo de Lectores / Galaxia Gutenberg: 153-160.

Vega, A. (2005). Arte y santidad. Cuatro lecciones de estética apofática. Navarra, Universidad Pública de Navarra.

WARner, M. (2016). "El yo perforado o la nada no es nulo", en Museo Universitario de Arte Contemporáneo, Anish Kapoor. Arqueología: Biología. Ciudad de México, Museo Universitario de Arte Contemporáneo/Universidad Nacional Autónoma de México/Editorial RM: 84-89. 